\title{
Letter to the editor regarding the article by Uzunoglu et al
}

\author{
Yasemin Savranlar • Mehmet Fatih Sönmez
}

Published online: 28 August 2011

(C) Springer Science+Business Media, LLC 2011

We read with great enthusiasm the recent study by de Uzunoglu et al. [1] entitled "Protective effect of L-carnitine versus amifostine against cisplatin-induced nephrotoxicity in rats." Uzunoglu et al. [1] demonstrated that amifostine or L-carnitine had no protective effect on cisplatin-induced nephrotoxicity in rat model. Furthermore, application of amifostine before cisplatin may even enhanced cisplatininduced nephrotoxicity histopathologically.

In the Uzunoglu et al.'s study, we see that the errors missed. These mistakes should be checked and corrected. Firstly, the number of animals in abstract and in materials and methods is different. It is fifty-seven in abstract and fifty-four in materials and methods. And another mistake is that cisplatin was abbreviated as CDDP at manuscript and figure legends but it is written CIS in Figure 1.

\section{Reference}

1. Uzunoglu S, et al. Protective effect of L-carnitine versus amifostine against cisplatin-induced nephrotoxicity in rats. Med Oncol 2010. doi:10.1007/s12032-010-9746-2. 